\title{
The experiences of people
} at the Komfo Anokye Teaching Hospital (KATH) in Ghana

\author{
Vida Maame Kissiwaa Amoah², Reindolf Anokye ${ }^{1}$, Enoch Acheampong ${ }^{1^{*}} \mathbb{0}$, Helina Rubby Dadson², Mary Osei ${ }^{2}$ \\ and Alberta Nadutey ${ }^{1}$
}

\begin{abstract}
Objective: Lower limb amputation not only causes major disfigurement, but renders people less mobile and at risk of loss of independence. Yet with appropriate rehabilitation, many people can learn to walk or function again and live high quality lives. This study sought to explore the experiences of patients with diabetes-related lower limb amputation at the Komfo Anokye Teaching Hospital. An exploratory study design was adopted using a qualitative approach and a purposive sampling to select 10 participants for the study. A semi-structured interview guide was used with an in-depth face-to-face interview. The interview was tape-recorded with an audio recorder while notes were taken in addition to the audio recording.

Results: There were varying degrees of experiences ranging from physical as well as psychological and economic challenges. Amputees had to cope with playing entirely new roles after the amputation. They also experienced some economic challenges which were as a result of their inability to work. Some of the amputees consoled themselves with the fact that, despite their condition, they were better than other people. Others believed that whatever happened was Gods doing and nothing could be done about it. This self-consolation and the belief in God helped them to cope.
\end{abstract}

Keywords: Life experiences, Diabetes related amputation, Ghana

\section{Introduction}

Amputation is the surgical removal of all or part of a limb or extremity such as an arm, leg, foot, hand, toe, or finger [1]. Lower limb amputation does not only disfigure, but renders people less mobile and may lead to loss of independence [2]. Despite advances in medicine and surgery, amputation continues to be a large problem among adults which has resulted in more than 900,000 people living with minor limb loss worldwide [3]. Most amputations occur as a result of Diabetes Miletus which is a metabolic

\footnotetext{
*Correspondence: caposterl@yahoo.com

${ }^{1}$ Centre for Disability and Rehabilitation Studies, Department of Community Health, Kwame Nkrumah University of Science and Technology, Kumasi, Ghana

Full list of author information is available at the end of the article
}

disorder characterized by chronic hyperglycemia [4]. It is currently afflicting 194 million people worldwide [5]. The prevalence of diabetic foot ulcer ranges from 1.0 to $4.1 \%$ in the US, $4.6 \%$ in Kenya, 20.4\% in the Netherlands [6, 7], between 11.7 and $19.1 \%$ in Nigeria $[8,9]$ and $20 \%$ in Iran [10]. Diabetic Foot Ulcer may become more common in the Tropics with the increasing prevalence of diabetes in Nigeria and Ghana [11]. It is believed that every $30 \mathrm{~s}$ a lower limb is lost somewhere in the world as a consequence of diabetes [12]. Diabetic foot complications are a leading cause of amputation and mortality in diabetic patients [13].

Lower limb amputation at the Komfo Anokye Teaching Hospital comprised of knee amputation $(n=23$; $22.1 \%)$, Rays amputation of the toe $(\mathrm{n}=15 ; 14.4 \%)$ and 
Hip de-articulation ( $\mathrm{n}=2 ; 1.9 \%)$ [14]. It is estimated that about 145,299 people have been amputated in Ghana [15].

Amputations are devastating because of the sudden change in body form and the difficulties associated with rehabilitation especially in developing countries like Ghana where prosthetic services are scarce [16]. Little has been done on the experiences of patients who have undergone diabetes-related lower limb amputation. This study was conducted to explore the experiences of persons living with diabetes related amputations to serve as a blueprint for further conclusive studies.

\section{Main text Methods}

The study was conducted at Komfo Anokye Teaching Hospital (KATH) in Kumasi, Ashanti region, Ghana. It is the second largest hospital in Ghana and the only tertiary health institution in the Ashanti region. The hospital has a child health, diagnostic, pharmacy, physiotherapy, oncology, polyclinics and diabetes units.

An exploratory study was conducted to serve as a springboard upon which further studies could be conducted and a qualitative research approach was used. Patients were selected if they had been amputated at the foot (including toes or partial foot); at the ankle (ankle disarticulation); below the knee (transtibial); at the knee (knee disarticulation); above the knee (trans femoral) and at the hip (hip disarticulation). Data were collected between December 2016 and March 2017.

Patients were selected if they were between the ages of 25-70 years (most patients or cases for non-traumatic amputation fell between this age range); spoke English, Fante and Twi (the languages the investigators could speak) and were present at the hospital at the time of data collection. Patients were excluded if they could not speak Twi, Fante or English; could not give their consent to be part of the study; had traumatic amputation and were under 25 years and above 70 years.

A Purposive sampling technique was used to recruit participants. Participant recruitment continued until saturation was achieved with the 10th participant where no new significant information was obtained. The variability, experiences and perceptions narrowed by the time the $10^{\text {th }}$ participant was interviewed. Also, the study addressed an obvious, clear topic, and the information was easily obtained from the participants, therefore fewer participants were needed.

A semi-structured interview guide which was designed for the purpose of this study was used for the study. The instrument was developed based on the research questions and 8 questions were asked. The interview was tape-recorded with an audio recorder in addition to field notes. All interviews were conducted face-to-face at the orthopedic unit of the Komfo Anokye Teaching Hospital and in the participant's homes, at a date and time which was convenient for them. The interviews were conducted in English, Fante and Twi and conducted by two of the investigators who have been trained on qualitative data collection. The interviews were pretested at Kumasi South Hospital using 5 participants. The pretest was used to evaluate the language competency and content validity of data collection materials and to estimate time length of full interview delivery as well as mark periods of respondent participant's fatigue.

The tape-recorded interviews were transcribed verbatim and later categorized into similar themes. The analyses was done manually using the thematic content analysis guided by Miles and Huberman's framework for thematic content analysis.

The authors divided the major themes into two categories which were physical experiences and coping strategies previously determined by the nature of the interview guide (Additional file 1).

\section{Results}

\section{Demographic characteristics of participants}

More males were part of the study as compared to females. Out of the 10 participants, $60 \%$ were aged 41-60 years; $70 \%$ were married and had attained formal education as shown in Additional file 2: Table S1.

\section{Physical experiences}

\section{Adjustment to amputation and present physical state}

Adjustment to amputation was difficult for a lot of the amputees as most of them found it difficult to accept their present physical state due to low adjustment rate and the difficulty in using walking aids. Others perceived their condition as better compared to previous condition.

\footnotetext{
"The feeling was bad; I always depend on other people to do everything". (Male Amputee 1).

"I felt good after my legs were amputated compared to when the wound was there". (Male Amputee 3).

"When I wake up and do not find anybody at home, I wait till they are back before doing anything." (Female Amputee 4).
}

\section{Changes in lifestyle}

Amputation changed patient's lifestyle and the males were particularly worried because they had to abandon their jobs because they were physically demanding which their current condition could not meet. 
"...As you can see, am the only person left in the house, I sleep and wake and use clutches to go out because I was asked to exercise..." (Male Amputee 4).

\section{Loss of everyday functional independence}

Functional independence makes it possible to perform daily living tasks without help. Participants who had been amputated did not have the ability to perform daily living tasks without the help of others. The female amputees were not happy with such limitations.

"If you want to bath unless someone fetch the water for you. Since I came I haven't gone to the bath or fetch water on my own...." (Female Amputee 2).

\section{Changes in family responsibilities/duties}

Participants stated that the roles that they played in the family has changed because they could no longer play work and paying utility bills.

"I have to go to work but I can't and now am unemployed, my family's feeding and education of my children are in the care of the woman and that is a problem..." (Male Amputee 5).

\section{Psychological/emotional experiences}

Amputation had some psycho-emotional impact such as feeling of being a burden, unimportant and useless on patients and their families.

"My wife knew that some people with diabetes had been amputated and didn't live for long, so when it happened she asked the doctor if I can survive" (Male Amputee 6).

"It is difficult because I have become a burden because people look after me which makes me somehow useless...." (Female Amputee 4).

\section{Economic experiences}

The survival of patients through the amputation process and afterwards is strongly dependent on the availability of financial resources. Patients experienced economic challenges which were as a result of their inability to work. One echoed that;

"It affected me because I lost my job and can no longer cater for my family which is a big problem for me..." (Male Amputee 2).

\section{Coping strategies}

\section{Self-consolation}

Some of the participants consoled themselves with the fact that, despite their condition, they were better than other people. This self-consolation helped them to cope.

"I take consolation in the fact that someone cannot even see. I say to myself look someone cannot see but if I can it should serve as encouragement for me... "(Female Amputee 1).

\section{Trusting in God}

Some of the amputees trusted in God, they believed that whatever happened was Gods doing and nothing could be done about it.

"I have faith in God, He created me and knows what is good for me so I have accepted it..." (Female Amputee 3).

\section{Dependence on immediate family members}

The immediate Family members, spouse and children provided support in the form of advice, financial assistance and helped amputees in managing the home.

"My family and children were very supportive financially and they are still taking care of me..." (Male Amputee 4).

\section{Discussion}

The study explored the experiences of individuals with diabetes-related lower limb amputation at the Komfo Anokye Teaching Hospital (KATH). The findings revealed that most of the amputees were males which corresponds with several findings in West Africa [1721]. It was evident that some of the amputees struggled with walking aids because it was something entirely new. This is similar to another study which revealed that basic movement and activities was a challenge for most victims of amputation [22]. However, in a study by Godlwana [23], people with Lower Limb Amputation's in the Johannesburg metropolitan area had no problem with mobility.

Amputation of a limb does not leave just a physical dent on an individual, but loads of psychological and emotional effects thus feeling useless because of the inability to do anything. This corroborates with the findings of De Godoy et al. [24] who found that the quality of life was generally lower for amputees. Surprisingly, some few amputees were not emotionally depressed as they were 
even happy for the loss of limb. According to Rybarczyk et al. [25], after many years of suffering with chronic debilitating diabetic foot ulcers, an amputation may result in improved quality of life for the patient, therefore individuals who undergo a lower limb amputation may not view it as a negative event.

Amputations had socio-economic effects due to loss of jobs and financial demands for medical care after surgery. Burger and Marincek [26] indicated that people with a lower limb amputation have problems returning to work.

This study found that not all amputees coped well with the condition as expected and this was supported by a study that lack of proper coping strategies could lead to psychological breakdown and affect management of the condition $[27,28]$. They believed that their situation was willed by God and expressed their gratitude to their creator for granting them life. A positive approach to conditions of amputees has a positive correlation with pain and total recovery [29-31]. Amputees relied on family and friends for their day-to-day activities and survival. The change in lifestyle due to physical incompleteness which may lead to anxiety and depression calls for the need for adequate support and rehabilitation.

\section{Conclusion}

Amputees had some physical experiences after the amputation. The males were worried as they could not work and cater for their families. Coping strategies were mostly, acceptance of current physical condition whiles others consoled themselves by comparing themselves to other people whom they perceived to be better than and some believed that whatever happened was Gods doing. Amputees were mostly dependent on spouse and children who provided support in various ways. This study will therefore contribute to the studies related to this area and provide a solid springboard for future studies (Additional file 3).

\section{Recommendations}

The study recommends proper and adequate counseling of prospective amputees by the hospital staff such that they will be well prepared for the changes that are likely to occur after amputation.

Also, Amputees should come together and form selfhelp groups to develop coping strategies and share problems together.

\section{Limitation}

The study design does not allow for a conclusive outcome and data was collected from a small sample which may have limited the chances of having varied responses. Whilst there may be limitations inherent in the study design and methods used, these by no means compromise the results reported. Being a qualitative study with the small sample size and mostly based on subjective answers limits the extent to which these findings can be generalized.

\section{Additional files}

Additional file 1. Instrument used for data collection.

Additional file 2: Table S1. Demographic characteristic of participants.

Additional file 3. Change of authorship form.

\section{Abbreviation \\ KATH: Komfo Anokye Teaching Hospital.}

\section{Authors' contributions}

The collection of data was done by the fifth and fourth authors ( $\mathrm{MO}$ and HRD). The secondary data compilation and review of study was done by the first author (VMKA). The second, third and sixth authors (RA, EA and AN) revised the manuscript thoroughly with their individual expertise. In the analysis of data, all authors played a significant part as well as in designing and preparing the manuscript. Proof reading and the final approval process was also shared accordingly among all authors and all authors have agreed to its submission for publication. All authors read and approved the final manuscript.

\section{Author details}

${ }^{1}$ Centre for Disability and Rehabilitation Studies, Department of Community Health, Kwame Nkrumah University of Science and Technology, Kumasi, Ghana. ${ }^{2}$ Department of Nursing, Garden City University College, Kumasi, Ghana.

Acknowledgements

Our gratitude goes out to the teaching staff of the School of Nursing, Garden City University College and the management and staff of Komfo Anokye

Teaching Hospital, Kumasi as well all amputees who participated in this study. Further thanks to all whose works on amputation helped in putting this work together.

\section{Competing interests}

The authors declare that they have no competing interests.

\section{Availability of data and materials}

A complete document of this study and its results can be found at the Library of the Garden City University College, Kumasi.

\section{Consent for publication}

After Participants were informed about the aim of the study, they gave their consent for the anonymous quotes to be published.

\section{Ethics approval and consent to participate}

The committee on Research at Garden City University College and the Komfo Anokye Teaching Hospital approved the study. Participants were informed about the aim of the study and its scope and sought their consent to participate. Verbal consent was taken from participants and the process was approved by the ethics committee after explanation. The identity of study respondents was kept confidential throughout the study. In order to maintain anonymity, participants' identity was not disclosed for this study. The administrators of the hospital approved the use of the facility for the study and Ethical Approval was obtained from them.

\section{Funding}

No external funding was received for the purpose of this study. All cost related to this research was covered by the researchers themselves. 


\section{Publisher's Note}

Springer Nature remains neutral with regard to jurisdictional claims in published maps and institutional affiliations.

Received: 14 November 2017 Accepted: 16 January 2018

Published online: 24 January 2018

\section{References}

1. DerSarkissian C. How can hepatitis $C$ affect your body? WebMD medical reference reviewed; 2016.

2. Gitter A, Bosker G, DeLisa JA. Physical medicine and rehabilitation: principles and practice. Philadelphia: Lippincott Williams \& Wilkins; 2005. p. 1326-54.

3. Ziegler-Graham K, MacKenzie EJ, Ephraim PL, Travison TG, Brookmeyer R Estimating the prevalence of limb loss in the United States: 2005-2050. Arch Phys Med Rehabilit. 2008;89(3):422-9.

4. Eastman RC, Javitt JC, Herman WH, Dasbach EJ, Zbrozek AS, Dong F, Manninen D, Garfield SA, Copley-Merriman C, Maier W, Eastman JF. Model of complications of NIDDM: I. Model construction and assumptions. Diabetes care. 1997;20(5):725-34.

5. Wild S, Kennon B, Leese GP, Cochrane L, Colhoun H, Stang D, Sattar N, Pearson D, Lindsay RS, Morris AD, Livingstone S. Reduced incidence of lower-extremity amputations in people with diabetes in Scotland. Diabetes Care. 2012;35(12):2588-90.

6. Bartus $\mathrm{Cl}$, Margolis DI. Reducing the incidence of foot ulceration and amputation in diabetes. Curr Diab Rep. 2004:4:413-8.

7. Nyamu PN, Otieno CF, Amayo EO, McLigeyo SO. Risk factors and prevalence of diabetic foot ulcers at Kenyatta National Hospital, Nairobi. East Afr Med J. 2003;80(1):36-43.

8. Ogbera AO, Fasanmade O, Ohwovoriole AE, Adediran O. An assessment of the disease burden of foot ulcers in patients with diabetes mellitus attending a teaching hospital in Lagos, Nigeria. Int J Low Extrem Wounds. 2006;5(4):244-9

9. Unachukwu C, Babatunde S, Ihekwaba El. Diabetes, hand and/or foot ulcers: a cross-sectional hospital-based study in Port Harcourt, Nigeria. Diabetes Res Clin Pract. 2007;75:148-52.

10. Fard AS, Esmaelzadeh M, Larijani B. Assessment and treatment of diabetic foot ulcer. Int J Clin Pract. 2007;61(11):1931-8.

11. International Diabetes Federation. The diabetic foot: amputations are preventable. Brussels: International Diabetes Federation; 2005.

12. Sicree R, Wild S, Roglic G, Green A, King H. Global prevalence of diabetes: estimates for the year 2000 and projections for 2030. Diabetes Care. 2004:27:1047-53.

13. Abubakari AR, Bhopal RS. Systematic review on the prevalence of diabetes, overweight and physical inactivity in Ghanaian and Nigerians. Public Health. 2008;122:173-82.

14. Kyei I, Dogbe J, Larsen-Reindorf R, Mensah S. The scope of non-trauma lower limb amputations at the Komfo Anokye Teaching Hospital, Kumasi-Ghana. MOJ Orthop Rheumatol. 2015;3(5):00108. https://doi. org/10.15406/mojor.2015.03.00108.
15. Chalya PL, Mabula JB, Dass RM, Ngayomela IH, Chandika AB, Mbelenge N, Gilyoma JM. Major limb amputations: a tertiary hospital experience in northwestern Tanzania. J Orthop Surg Res. 2012;7(1):18.

16. Gallagher P, MacLachlan M. Development and psychometric evaluation of the Trinity Amputation and Prosthesis Experience Scales (TAPES). Rehabilit Psychol. 2000;45(2):130.

17. Essoh JB, Bamba I, Dje Bi Dje V, Traore A, Lambin Y. Limb amputations in adults in an Ivorian Teaching Hospital. Niger J Orthop Trauma. 2007:6:61-3.

18. Nwankwo OE, Katchy AU. Surgical limb amputation: a 5 year experience at Hilltop Orthopaedic Hospital Enugu, Nigeria. Niger J Orthop Trauma. 2004;3:139-49.

19. Jenyo MS, Diya KS, Olakulehin OA. Limb amputations in Osogbo, Nigeria. Afr J Trauma. 2004;2:80-2.

20. Solagberu BA. The scope of amputations in a Nigerian teaching hospital. Afr J Med Med Sci. 2001:30:225-7.

21. Kidmas AT, Nwadiaro CH, Igun GO. Lower limb amputation in Jos, Nigeria. East Afr Med J. 2004:81:427-9.

22. Bosmans JC, Suurmeijer TP, Hulsink M, van der Schans CP, Geertzen JH, Dijkstra PU. Amputation, phantom pain and subjective well-being: a qualitative study. Int J Rehabilit Res. 2007;30(1):1-8.

23. Godlwana LL. The impact of lower limb amputation on quality of life: a study done in the Johannesburg metropolitan area, South Africa. Dissertation. Faculty of Health Sciences, University of the Witwatersrand, Johannesburg; 2009.

24. De Godoy JM, Braile DM, Buzatto SH, Longo O, Fontes OA. Quality of life after amputation. Psychol Health Med. 2002;7(4):397-400.

25. Rybarczyk B, Nicholas JJ, Nyenhuis DL. Coping with a leg amputation: integrating research and clinical practice. Rehabilit Psychol. 1997:42(3):241.

26. Burger H, Marinček $\breve{C}$. Return to work after lower limb amputation. Disabil Rehabilit. 2007;29(17):1323-9.

27. Livneh H, Antonak RF, Gerhardt J. Psychosocial adaptation to amputation: the role of sociodemographic variables, disability-related factors and coping strategies. Int J Rehabilit Res. 1999:22(1):21-32.

28. Mikulinecer M, Florian V. Coping and adaptation to trauma and loss. In: Zeidner M, Endler NS, editors. Handbook of coping: theory, research and applications. New York: Wiley; 1996. p. 554-72.

29. Hanley MA, Jensen MP, Ehde DM, Hoffman AJ, Patterson DR, Robinson LR Psychosocial predictors of long-term adjustment to lower-limb amputation and phantom limb pain. Disability Rehabilit. 2004;26(14-15):882-93.

30. Whyte A, Carroll $\perp$. The relationship between catastrophizing and disability in amputees experiencing phantom pain. Disability and Rehabilit. 2004:26(11):649-54.

31. Hawamdeh ZM, Othman YS, Ibrahim Al. Assessment of anxiety and depression after lower limb amputation in Jordanian patients. Neuropsychiatr Dis Treat. 2008:4(3):627.

\section{Submit your next manuscript to BioMed Central and we will help you at every step:}

- We accept pre-submission inquiries

- Our selector tool helps you to find the most relevant journal

- We provide round the clock customer support

- Convenient online submission

- Thorough peer review

- Inclusion in PubMed and all major indexing services

- Maximum visibility for your research

Submit your manuscript at www.biomedcentral com/submit
Ciomed Central 